\title{
Management of Wellness by Physical Activities
}

\author{
Dr. Hemadri I. Tikawala, Mr.Mukesh R.Goyani, Mr. Jignesh Vaghela \\ (R.V. Patel \& V.L. Shah College of Commerce, Amroli, Surat) \\ "Today we need Bhagwad Geeta but also required football fields." Swami Vivekand "If Health is Lost \\ everything is Lost."
}

\begin{abstract}
Man is a basic unit of society. In society everyone has to live and generally cooperate with others. A physically well or fit member of society, instead of being a burden on it, will be able to contribute his might in the achievement of its particular goals and objectives. A physically well individual can prove a better worker, technician, doctor, engineer or a parent and can contribute towards the betterment of self, family or the institution where every works.

Physical wellness is an ideal concept of physical fitness and includes both external as well as internal component of a person's fitness or wellness. The external factor of wellness or fitness may be misleading because a person may not be as fit as one appears to be outwardly. In some cases, person having some mental problems appear to be very healthy. Similarly, the achievement of a particular task mayn't reveal the real status of his health. Therefore, the internal component of well being i.e., physical, mental, and social well being is very important in management of wellness. Such factors are the foundations of health. Therefore, proper health is an essential part of wellness also includes the health factor and is therefore something more than mere wellness for a particular task. A state of well being can only help a person in leading a better quality life. Physical fitness is one aspect of wellness. Wellness isn't only concerned with physical fitness but also concerned with mental fitness; social fitness and emotional fitness are also its essential aspect. In fact, wellness is the capacity of an individual by which he leads a well
\end{abstract} balanced life.

\section{Introduction}

Man is a basic unit of society. In society everyone has to live and generally cooperate with others. A physically well or fit member of society, instead of being a burden on it, will be able to contribute his might in the achievement of its particular goals and objectives. A physically well individual can prove a better worker, technician, doctor, engineer or a parent and can contribute towards the betterment of self, family or the institution where every works.

Physical wellness is an ideal concept of physical fitness and includes both external as well as internal component of a person's fitness or wellness. The external factor of wellness or fitness may be misleading because a person may not be as fit as one appears to be outwardly. In some cases, person having some mental problems appear to be very healthy. Similarly, the achievement of a particular task mayn't reveal the real status of his health. Therefore, the internal component of well being i.e., physical, mental, and social well being is very important in management of wellness. Such factors are the foundations of health. Therefore, proper health is an essential part of wellness also includes the health factor and is therefore something more than mere wellness for a particular task. A state of well being can only help a person in leading a better quality life. Physical fitness is one aspect of wellness. Wellness isn't only concerned with physical fitness but also concerned with mental fitness; social fitness and emotional fitness are also its essential aspect. In fact, wellness is the capacity of an individual by which he leads a well balanced life.

Wellness program stress on proper nutrition, no smoking, no alcohol or drugs, weight control and stress management. Sports and games provide an ideal time to introduce the concept of wellness to young children. A healthy body produces effective performance and allows the child to get maximum enjoyment.

Most of the parents in our country want to maintain and improve the health of their children that's why we take them to the best doctors. But unfortunately, we do little help in preventing dangerous diseases that may strike them later in life.

Wellness is an ideal concept of both external as well as internal components of an individual fitness. Today every individual desires to possess a healthy life but due to rapid industrialization growth in population, increasing numbers of vehicles, continuous and regular use of fertilizer, chemicals, pesticides etc. for better production of agricultural products, malpractices applied for earning more profit etc... are directly influencing the health.

Watching T.V. for a longer duration (Couch Potatoes), using computer, driving or boarding car even for a short trip, using elevators and lifts in the markets\malllduty place and even in multi-stories residential apartment; these all contribute to our in active life. 
On the other hand due to growing use of passive technological practices in habitual life is responsible for high level of physical inactivity among all the age groups. Research result recognized that almost $75 \%$ populations aren't active enough to gain the health benefits.

In recent the concept of 'Wellness' staying healthy and achieving the highest potential for well being has become very popular. In India, some corporations have developed wellness program in an attempt to keep their employees healthy and to reduce in Insurance premium.

\section{Theory of Wellness}

Wellness is a recent concept denoting the integration of health and fitness (Physical, Mental, and Intellectual, emotional and social) that expands one's potential to live and work effectively and to make significant contribution to society.

\section{Astonishing Facts}

In 1995 alone, non-communicable diseases contributed 60\% i.e. 31.7 million of death in the world. In 1998 itself there were 16.6 million deaths from cardio-vascular disease in the world. Hypertension alone affects $20 \%$ of the adult population worldwide. After a decade as per the modern status, in India, presently, 35 cores peoples are suffering from diabetes and 20 cores people having hearts problems. Some facts published in "Times of India".

- Almost $66 \%$ of all death in 2020 are unlikely to be from unceasing diseases

- Percentage of Cardio-Vascular patients succumbing to death is currently estimated at $30 \%$ within the age group of 35 to 65 .

- Around 57.2 million people will be affected by diabetes by the year 2025 .

- India's per capital expenditure in health is estimated at $\$ 23$.

\section{Components of Management Wellness}

Generally, wellness management depends upon many factors but the most significant component of wellness are:-

\section{Management of Balance-Diet}

Most of the persons don't know what management of balance-diet is? Even we don't have time to take diet at proper time due to work or professional load. Those who think of taking balance-diet don't get it because of reduced nutritious values of the food stuff. Nutritious values becoming reduced due to the use of chemicals, fertilizers, Pesticides, due to use of colour for the beatification of fruits and vegetables also due to application of harmful tactics for ripening the undeveloped fruits and vegetables.

On the other hand most of the peoples are having poor eating habits i.e. taking chowmin, powbhagi, noodles, chanized food, burger, bakery items, pasta, unhygienic drinks etc... and all these if eaten for a longer time carry out affect the health. Therefore, having balance diet seems to be just impossible and or course "It's not in our Control" to a great extent.

\section{Management of Positive Attitude and Steady Mind}

In the recent life style it is very difficult to achieve positive attitude and steady mind. Students face this crisis due to excess academic load and parental level of expectation. But it's very difficult to find a person without tension, worries, depression, frustration and much such emotional instability. But again this component also "Not seems to be in our control" because its depend upon way of philosophy.

\section{Management of Proper Relaxation}

Medical science says that proper rest to the body is essential need. At least 5 to 8 hours of absolute rest is advised by the Doctors and scientists but due to the aforesaid reason the mind and the body don't get enough rest for relaxation.

\section{Management of Daily Exercise}

This is one amongst the essential requirement of wellness but physical exercise tends to decline significantly with age group. On the basis of research it has been concluded that:

$>$ Hardly $30 \%$ to $40 \%$ persons of the total population are conscious about the exercise and believing in exercise.

D Almost $1 / 3^{\text {rd }}$ of the total population are aware of the significant of the exercise

$>$ Females are least believed in doing exercise in daily basis

$>$ Doctors and Scientists advise to under go physical exercise regularly for maintaining healthy mind and healthy body.

> Most of the Non-communicable diseases like obesity, diabetes, stroke, high blood pressure, depression, respiratory problem, and heart diseases may be caused due to inactive life style. 


\section{VIII. $\quad$ Factors Affecting Physical Wellness}

\section{Training}

In physical wellness and fitness analyze the most significant factors are..

The training also affects the physical fitness. If the training isn't up to desirable level, it will be incapable for getting better his physical fitness.

\section{Systematic way of Training}

The way of training should be scientific to maintain the physical wellness but if the way of training isn't scientific, the physical fitness may be decreased.

\section{Daily Exercise}

The main factors are daily exercise. Which influence the corporal strength of anyone person.

\section{Rest \& Relaxation}

If proper rest and relaxation are done, there will be positive effect on the physical fitness of an individual but if anyone doesn't have proper rest and relaxation his level of physical fitness may decline.

\section{Appropriate Habituation}

Habituation has a direct relationship with physical fitness.

\section{High-quality Posture}

Everyone likes the high-quality posture of an individual. It is also the symbol of wellness. The person, who doesn't have good posture, tends to have lower level of physical fitness.

\section{Environment}

The environment in which includes Climate, temperature, attitude, communal and civilization factors, affects the physical fitness of a person.

\section{Standard of Living}

The people, who have low standard of living, are likely to have less physical fitness. Standard of living plays an indirect role in influencing the physical fitness.

\section{Stress \& Tension}

Stress \& tension decrease the psychological power of an individual, which in turn, reduce the level of physical fitness as well as wellness.

\section{Drugs}

Drugs have a specific effect on physical fitness of a person. But later on these drugs have a negative influence on the physical fitness of a person.

\section{Intoxication}

Intoxication doesn't have a positive effect on physical fitness. Specifically it has negative effect on coordinative abilities of a person. Because of intoxication a person loses his balance and his control nervous system also loses its central over body.

\section{Balanced Diet} wellness also.

Balanced diet isn't only improves the level of fitness but also helpful in maintaining the physical

\section{Benefit of Regular Exercise}

Some components are so far that except this component of wellness all other components are almost not in our control. But this component is definitely in our control. Moreover, for daily exercise we don't need to spend money, this is $100 \%$ free cost. Only interest is to be generated within the self. It is neither expensive nor it requires much space. So, benefit of exercise can be classified into the following.

\section{Corporal Benefit}

- $\quad$ Sourced personality

- Better appearance and smart look

- Daily and continuity of exercise for a longer period gives well again posture and balance

\section{Physiological Benefit}

- Well-organized functioning of all the system of the body

- Proper growth and development

- Improves sexual abilities

\section{Psychological Benefits}

- Proper awareness

- Sound mind

- Better self-esteem

- Enhance intellectual ability

- Felling of well being 
- Enhance self confidence

- Relief from negative emotions like stress, frustration etc...

4. Health associated Benefit

- Control weight hence prevents obesity

- Enhance appetite and better digestion of the food.

- Maintains blood pressure and cholesterol level

- Increase the body immunity power

- Freshness and energetic feeling

- Sound sleep mental measures

- Acts as preventive measure against various non-communicable diseases etc...

- Strong muscles, ligaments, bonus etc..., hence prevents from injuries.

Method for improving wellness

Good quality Nutrition

- A health and nutritious diet helps to maintain an ideal body weight for sport and improves performance

- It reduces the working efficiency of an individual and finally wellness of a person can be improved

- Obesity comes due to over eating and by not doing physical exercises.

No to Alcohol, Drugs \& Smoking

- Always say 'no' to alcohol and drugs if you want to improve wellness style of life

- Smoking is harmful to the lungs and leads to heart diseases and decreases the efficiency in any type of work. It may cause mouth, larynx, throat and easophagus cancer

- Nicotine in cigarette cause blood vessels to narrow and further inhabits blood flow. Therefore, muscles can't get sufficient oxygen for sustained and vigorous activity.

\section{Sport and Games}

- Researchers in this field indicate that sports and games enhance the growth and development of mind.

- These components reduce lower back pain, risk of various diseases such as diabetes and heart problems etc...

- Contribute to wellness by developing the various physical fitness components such as strength, speed, endurance, flexibility, and coordinative abilities.

- To lead a life with fun and frolic enhances wellness. Sports and games one meant to be fun, frolic and break from the routine of life. It helps to reduce stress and tension.

\section{Benefits of Physical Activities}

- Everyone wants to maintain one's physical fitness because owing to physical fitness, one can perform the routine work easily. That's why it is said that physical fitness adds years to one's life.

- Fitness and wellness are necessary for a common man too.

- Improves posture and personal appearance and also changes our lifestyle or way of life

- Medical doctors indicates that physical fitness maintains muscular tissue, decreases the risk of injury and reduces lower back pain also,

- Researcher studies in the field of physical fitness indicate that the children, who established physical fitness in early life, are likely to remain active in future.

- Physical fitness is important in the daily activities of walking, running, lifting and carrying.

\section{Conclusion}

On the basis of the aforesaid study it has been concluded that many factors are responsible for the wellness, but the most significant factors are proper diet, positive attitude, proper rest of the body and daily exercise. Expect the last component of the wellness all other components are very difficult to be made available or achieved as because they aren't in our control. But the last component ex. doing exercise regularly is in our control and is available free of cost one must understood the benefits of regular exercises and gives forty minute of 24 hours to keep oneself healthy for long life and efficient work ability.

So in short, it can be concluded that physical fitness is necessary for everyone from every walk of life. Its level may vary from a common man to that of an international athlete. More and more stress should be laid down upon the physical fitness of individual. Only the physical fitness and wellness of people can make a nation strong.

[1]. Pork, K (1994), Text Book of Preventive \& Social medicines

\section{Reference}

[2]. Kunsal D.K.(1999) Test \& Measurement in Sports \& Physical Education.

[3]. Sharma V.D. (2003) Introduction to Physical Health Education.

[4]. Kamlesh M.L. (2001-02) Health \& Physical Education

[5]. Times of India, National News Paper (31 ${ }^{\text {st }}$ Aug. 2011). 